\title{
Applying an Ethical Judgment Model to the Case of DDT
}

\author{
Tom Børsen and Søren Nors Nielsen
}

\begin{abstract}
While most chemicals produce, or have produced, direct and intentional effects, many may also cause significant unintended outcomes. In this regard, chemicals are ethically ambivalent. It is not easy to balance the positive and negative consequences, nor is it straightforward to include uncertain future effects within an ethical analysis. Therefore, it is pertinent to develop and implement a method for identifying, assessing, and balancing the ethical issues associated with the production and use of chemical substances. Such a method for accommodating an ethical evaluation is presented in this paper, being tested and exemplified using the case of DDT. Within the DDT case three major clusters of ethical problems are identified: the first concerning environmental ethics while another relates to the impact on human health, including, in particular, the lethal, carcinogenic, and sub-lethal aspects introduced by suspected endocrine disrupting effects. The third ethical concern focuses on the subject of justice and the distribution of risks, costs, and benefits.
\end{abstract}

Keywords: Ethical judgment, environmental ethics, industrial chemicals, chemical boomerangs, DDT.

\section{Introduction}

The Industrial Revolution has been followed throughout the $20^{\text {th }}$ century by an ever-increasing development of new products and technologies. The rapid materialization brings with it an adjacent evolution of new artificial chemicals which often differ considerably to naturally existing compounds, resulting in them being referred to as xenobiotics. Industrial chemical substances have ethical significance because of both their usefulness and the unintentional effects they pose to public health and the environment. This has been recognized and addressed in research journals such as HYLE (Davis 2002, Preston 2005) and Science and Engineering Ethics (Parke 1995, Beamon 2005), as well as in reports from international organizations such as the United Nations 
Environmental Programme (UNEP 2015) and the European Environmental Agency (EEA 2001, 2013).

While it may appear strange that industrial pollutants such as DDT continue to be produced and used today, the initial development of such substances was never driven by the intention to harm human health or the environment. Instead, they were developed to serve beneficial purposes with each pollutant boasting at least one useful quality - the character of which being dependent on the particular chemical in question. Some were developed to increase the production of foods, such as pesticides or growth promoters, while others, such as those administered as medicine, were intended for improving health conditions. Further examples include chemicals used for the extraction and synthesis of other chemicals, or substances used for cleaning processes. In short, the vast majority of these new chemicals have been developed with the intention of contributing to the improvement of life conditions. It is only within the last 30 to 40 years, as a result of increased usage, that the large number of indirect and unforeseen effects have been disclosed to us.

As with any other technology, industrial chemical substances are, under many circumstances, beneficial to their users. They contribute as solutions to societal problems and as such allow political visions to be materialized. However, if used intensively, the chemicals can severely damage the health of both humans and the environment. The problems faced by such bittersweet substances are the consequence of an uncritical faith in human control over nature that cannot be upheld as an underpinning principle for further technological development.

The discovery of secondary effects of the otherwise beneficial use of chemicals was influenced by the publication of Rachel Carson's important book Silent Spring from 1962. The book drew public attention to the unforeseen and negative consequences of the use of industrial chemicals, especially DDT. Silent Spring criticized both what Georg Henrik von Wright calls the 'myth of progress' and what the Danish biologist, Jesper Hoffmeyer, refers to as the 'technical fix'. The myth of progress names a widespread temptation to sacrifice established ethical orientation systems and functioning practices in exchange for everything that is new, technical, and unconquered, while the technical fix refers to technical problem-solving strategies that apply technical means which temporarily solve a problem without noticing the longterm unforeseen consequences on, for example, the environment or public health. The use of DDT without taking into account the unforeseen and unwanted health effects is an example of a technical fix.

Industrial chemical substances have been named 'chemical boomerangs' (Børsen Hansen 2005, Petrosyan 2011) - compounds developed with the intention of solving individual or social problems yet also containing unfore- 
seen negative (eco)toxicological effects, such as being potential contaminators of air, water, sediments, soil, plants, animals, and humans. In other words, these compounds come back like boomerangs to create new problems that call for further problem-solving. DDT is an example of a chemical boomerang.

The metaphor is striking: as we send something out, we also must expect to get it back. When longer distances are involved, we can even talk about 'chemical sputniks' - chemicals that have been transported through the atmosphere and that condense in colder climatic conditions through 'polar distillation' (Børsen Hansen 2005). This condensation means that indigenous peoples and animals in the Polar Regions (Siberia and the Arctic) have greater exposures to DDT even though there is no manufacturing in these areas.

Scientists, engineers, and decision-makers can no longer assume that technology overall is purely beneficial to humans. Technology has a dialectical nature - holding the potential both for the improvement and for the degradation of the human condition. This nature can be further explored using the ancient mythology of Hubris and Nemesis. In Greek mythology, hubris refers to dangerously over-confidence in ones' personal qualities leading to behavior that defies the norms protected by the ancient gods. Nemesis refers to the revenging gods' punishment of the perpetrator of hubris. If one does not respect technology's dialectical nature, and only focus on the technology's positive potential, one commits hubris. The myth can be translated into a relevant lesson for the use of DDT: undesirable consequences for the environment and society - Nemesis - arise as a result of uncritical and intensive use of DDT - hubris (Hard \& Jamison 2005).

\section{A Method for Proper and Quick Ethical Analysis}

This paper presents and applies a model developed at Aalborg University to conduct a quick and proper ethical analysis of issues and dilemmas related to the use of technology (Børsen \& Damborg 2015). In the paper, we will show that the method can also be applied in the ethical analysis of industrial chemicals. This is achieved by applying it to a case study of DDT, one of the chemicals regulated by the Stockholm Convention (see below).

The model is useful for chemists, chemical engineers, chemistry students, and others who want to make robust ethical judgments of the uses of a chemical substance by splitting the judgment process into four steps:

1. Identification of intended beneficial consequences, potential misuse, unintended adverse side-effects, and long-term consequences for society. 
2. Linkage of intended consequences, misuse, adverse effects, and cultural implications of the uses of the substance to appropriate ethical values.

3. Identification of ethical dilemmas related to specific uses of the chemical compound under assessment.

4. Formulation of appropriate technological and institutional design criteria that can resolve the identified ethical dilemmas.

We will apply the method to the case of DDT to exemplify how industrial pollutants can be analyzed ethically. Ethical analyses of the uses of different chemical compounds will of course not lead to identical ethical estimates. All chemical compounds have their individual properties and uses.

\subsection{Ethical values}

Ethical values play a central role in the analytical tool presented here. An ethical value is understood as a normative criterion against which one can compare the wider consequences and circumstances of use of a given chemical compound. Do uses and misuses, resulting in both short and long term effects, align with or violate different ethical values? In this paper, we have formulated a list of nine ethical values against which one can compare the uses of chemical substances. The list was constructed as follows.

The model is inspired by the so-called common-sense morality that can be traced back to Aristotle and Cicero, and through Aquinas to Kant and Ross. The ambition of common-sense morality is to balance ethical concerns which point in different directions and to formulate ethical compromises that all affected parties can accept. Common-sense morality is an ethical theory differing from many other ethical theories by not providing universal answers or decision methods. The ethically correct action is context dependent, where one must independently evaluate their options and choose what seems ethically most correct in a context of conflicting concerns. As the name 'common-sense' implies, this ethical theory cherishes common-sense and believes in the ability of humans to make judgments that are as informed and as reasoned as possible. On one hand, common-sense morality accepts that established ethical approaches reflect legitimate ethical concerns. On the other, it does not insist on only one ethical principle but instead emphasizes ethical reflection and common-sense. Common-sense can be understood as what Aristotle named phronesis - practical wisdom and functioning judgment. Phronetic judgment strives after the good life and the individual or collective ability to define actions pointing in that direction, in a context of contradictory but legitimate values.

This ethical approach takes a number of ethical concerns into account. A central aspect is the desire to combine and balance different ethical concerns of involved stakeholders. The founders of common-sense morality Tom L. 
Beauchamp and James Childress suggest that the fulfillment and balance of four ethical principles - respect for autonomy, utility, minimal harm, and justice - can guide decisions regarding concrete ethical dilemmas (Beauchamp \& Childress 2001). Beauchamp and Childress' value of minimal harm is here split up into 'safety' and 'security', which takes into consideration, respectively, unintended and intended harm.

When assessing industrial pollutants, the four original ethical standards of common-sense morality need to be supplemented with ethical values originating from environmental ethics. Hence, we have included three different ethical principles from this branch of ethics: the precautionary principle, which is a well-established concept in regulation of the European Union (EU 2000); stewardship for the Earth which originates in Hans Jonas' philosophy (1984); and Respect for nature which is extracted from Arne Næss' writings on deep ecology (1973).

The identification and selection of the ethical values most relevant for this analytic tool has been an iterative process. The combination of the original four principles of common sense morality combined with environmental ethical standards have been discussed at two seminars at Aalborg University and with students at an annual $\mathrm{PhD}$ course on ethics and social responsibility for engineers and scientists. These discussions have shown that ethical values inspired from Aristotelian ethics were not present, and therefore, two Aristotelian ethical standards have been added: humility and social stability.

In Table 1, we have included definitions of the ethical values used in the analyses. The list is not complete. New values can be added if users of the model find other values more relevant to their analysis. The table is ordered with the most individualistic and anthropocentric values placed at the top.

Table 1. Ethical values for evaluating of the use of industrial chemicals

\begin{tabular}{ll}
\hline Ethical value & Description \\
\hline Autonomy & $\begin{array}{l}\text { Everyone has a right to self-determination as long as it does not } \\
\text { prevent others from their right to self-determination. Autonomy } \\
\text { can be deduced from Kant's categorical imperative: No one must } \\
\text { be treated only as a mean and not also as an aim in themselves. }\end{array}$ \\
Safety and & $\begin{array}{l}\text { Everybody has the right to be protected from damage, and safe- } \\
\text { guarded from illness, hunger, accident and other dangers. This }\end{array}$ \\
& $\begin{array}{l}\text { value encompasses protection from undesirable events. Some- } \\
\text { times a distinction between safety and security is made where } \\
\text { safety refers to the right to be safeguarded from unintentional } \\
\text { harm, and security refers to the right for protection against inten- } \\
\text { tional harm (e.g. from terrorism) }\end{array}$ \\
& Here we include two different definitions: (1) Just actions are to
\end{tabular}


Utility This ethical value has the foreseeable consequences in focus, and states that the ethical correct action is the one that generates the maximal well-being for the highest number of people. Well-being can be defined in different ways: as the feeling of hedonistic pleasure, realization of personal potential, a prosperous life, etc.

Humility This ethical value is the anti-thesis to committing hubris. One commits hubris when one loses contact with reality and overestimates one's own competencies, does not listen to criticism and thinks one-dimensionally without giving alternatives any consideration. According to Greek myth one will be punished by Nemesis if one commits hubris. One is humble when one is selfrestrained.

Social stability This ethical value focuses on how the various parts of society fit together, and strives for establishing equilibrium by balancing different aspects and interests, and as a last resort forcing out extreme ideas and individuals that disagree with popular opinion.

Precautionary principle

This principle states an action should not be undertaking if there are reasonable grounds for concern, though no scientific evidence, for it having dangerous effects on the environment, humans, animals, or plant health.

Stewardship for This ethical value claims that humans are responsible for the the earth world, and therefore are obliged to take care of it by shaping trajectories of social-ecological change at local-to-global scales to enhance and balance ecosystem resilience and human well-being. It has religious origins, as it can be derived from the believe that humans are guardians of God's creation. Nature and natural resources are considered as a gift.

Respect for According to this value all forms of life have intrinsic or inherent nature value and are to be respected for their own sake. Humans are part of nature and the well-being and flourishing of human beings are not considered more important than the well-being and flourishing of other forms of life. Diversity of different life forms are contributing to the well-being of both individual species and individuals. This value derives from the notion of environmental rights.

David B. Resnik (2012) has constructed a similar list of ethical standards. Both Resnik's list and our list include the ethical values of utility, justice, stewardship, and precaution. In addition, Resnik's includes human rights which overlaps, to a certain extent, with this paper's listed values of autono- 
my and safety/security. Resnik's value is broader and includes all human rights, whereas our list focuses on two specific human rights - autonomy and safety/security. Furthermore, Resnik includes animal welfare in his list of ethical values which may be considered as being one element among the many included in this paper's value of respect for nature - the latter being less restricted to just animals that can feel pain, but instead treasures all life. Finally, Resnik includes sustainability which is a standard including environmental, financial, and social aspects. Our value of social stability focuses on the social sphere whose stability is affected by environmental and financial parameters. Another significant difference is that Table 1 above includes the ethical standard humility which has no counterpart in Resnik's list.

\section{Demonstration of the Method: The Case of DDT}

DDT was invented in 1873, and has thus been known since the early days of synthetic organic chemistry. Its toxic effect on insects was discovered more than 65 years later in 1939 by the Swiss chemist Paul Hermann Müller who, in 1948, was awarded the Nobel Prize in Physiology and Medicine for the discovery. The chemical was first applied outside the laboratory during World War II, where it was used to fight various insect borne diseases such as malaria and typhus (Bouwman et al. 2013). Following the war, DDT continued to be used in the fight against malaria but was also quickly conscripted into use as an agricultural insecticide - offering a potential solution to the issue of feeding the rapidly increasing global population. The application of DDT within agriculture promised increased food production while being seemingly harmless to human health. The future was to tell another story.

In the following, we apply the ethical analytical tool on the uses of DDT, step by step.

Step 1: Identification of intended and beneficial consequences, potential misuse, adverse effects, and long-term consequences for society

\section{Intended benefits}

One key application of DDT (as well as other pesticides) has been to maintain crop yields by protecting plants from insects. DDT is acutely toxic to insects and is therefore applied to kill the pests or prevent outbreaks, particularly in intensive farming systems where only a few crops are produced. According to Aktal et al. (2009) an almost four-fold increase in Indian food- 
grain production is estimated to be a result of such pesticide use from the late 1940 s to the late 1990 s.

Another key application of the chemical is in the prevention of diseases such as malaria, dengue fever, and Zika fever. Insects in these cases act as carriers, or vectors, of life threatening diseases which are typically prevalent in the tropics. The insects most responsible for such diseases are often mosquitoes but can also include flies and ticks. Mosquitoes of the genus Anopheles can transfer Plasmodium sp. parasites to humans by means of their bites, causing several types of malaria which can lead to fever, fatigue, seizures, or even death. The numbers of malaria infections per year is estimated to be around 300 million with a corresponding loss in GDP of 12 billion US\$, with most cases affecting developing countries (UNICEF 2004). The dengue virus also causes an unpleasant fever, while the Zika virus is suspected to cause microcephaly in babies whose mothers have been infected during pregnancy. A third group of diseases, represented by the typhoid bacteria, are not very persistent in the environment and hence depend on transfer, by means of insects, for their spread. Typhoid bacteria cause aches and pains, fever, constipation, or diarrhea. DDT use can be very effective in controlling the insects carrying the disease, at least initially.

Malaria, dengue, and Zika virus do not directly discriminate between humans, but there seems to be definite links to the social and geographical conditions in which the individuals live. For example, malaria is typically spread at certain levels of altitude with the culprit mosquitos being attracted to open, still, and fresh water areas. These conditions are commonly associated with areas of low living standards, such as poor communities - typically squatters - situated close to pools of rain and waste water in areas where no sewer systems have been established. Malaria also tends to be most common in developing countries due to a lack of public health infrastructure, and particularly affects the poor who cannot afford protective measures or medicines. In these areas, governments can achieve greater and cheaper levels of malaria protection in principle by spraying DDT in houses and gardens.

\section{Unintended adverse impacts}

Extensive evidence shows that exposures to DDT, whether as a pesticide or a disease control agent, can cause ecological and human health effects. DDT belongs to a group of chemicals known as Persistent Organic Pollutants (POPs). POPs are organic chemicals, i.e. consisting largely of carbon, that have high molecular weight, are lipophilic, and have a propensity to evaporate and disperse over long distances. These compounds are persistent, i.e. hard to break down, and will therefore remain for a long time within the environment or human bodies. They disperse easily and are unfortunately toxic to both humans and wildlife. 
DDT is persistent with a half-life time of 2 to 15 years. Its residues may be found for decades in soil, from where they can merge within organisms and later be transferred to consumers by means of food consumption. The chemical's properties make it bind efficiently to organic liquids or solid matter, fats, and fat tissues, and hence offer great potential for bio-concentration in organisms and for bio-magnification by up-concentration through the food chain: Plants treated with the chemical are eaten by plant-eating organism where it accumulates in fat tissues. The organisms are eaten by predators leading to even higher concentrations of DDT in the predator's bodies. Small predators are eaten by other predators resulting in further increase in concentration.

DDT is suspected of having a variety of sub-lethal effects. The chemical is mutagenic and therefore suspected to be carcinogenic, and has had toxic effects on internal organs and on the neuronal system in test organisms. The compound and its many derivatives have an endogenic effect in the human body and interfere with the hormonal system and associated with reproductive and developmental problems, e.g. incomplete development of sexual organs. It often hampers reproduction (Borgå et al. 2001, Leblanc 1995, Strandberg et al. 1998, Wang \& Wang 2005) and can lead to abnormal development in offspring. Such problems are also seen in wildlife and likely underpin observations quoted in Rachel Carson's Silent Spring (1962), where predatory birds, such as eagles, produce less offspring. This strengthens the case that the ethical aspects of DDT also concern nature. Endocrine disrupting effects are, in general, observed over a wide range of organisms - both vertebrates and invertebrates. The potential danger is that DDT may have an indirect but dramatic effect on the ecosystem structure by breaking essential links and transfers within the ecosystem network.

\section{Misuse}

DDT use is historically associated with rapidly growing resistance by pests. In both agriculture and disease control, farmers and public health agencies have incentives to use high doses of DDT to achieve 'better' results more quickly. There are several obstacles to such an approach. The recommended dose alone led to the growth of resistance among populations of 'target organisms' or the insects being controlled. This means that the organisms intended to be killed by the treatment become tolerant to higher and higher concentrations, or can even become insensitive to the compound used. A natural selection of pest organisms takes place: if some organisms can survive being sprayed with DDT, they are more likely to reproduce and pass their traits on to their offspring. Over successive generations, a larger proportion of the pest population can tolerate DDT, which then makes the chemical solution less effective. Furthermore, because DDT is indiscriminate in its 
effects, it can harm many 'non-target organisms' as well. For instance, soil worms that are in general beneficial to soil conditions or even natural predators of the target pest are also affected by pesticide use. When the undesirable effects of over-intensive use of DDT becomes known, the use becomes referred to as intentional misuse.

A similar type of misuse has been observed in agriculture, and involves an increasing frequency of use of DDT with a precautionary purpose, i.e. not suppressing pests as such but preventing potential outbreaks. As a consequence, the crops are under more or less permanent treatment. This misuse is often stimulated by the fact that consultants providing advice to farmers are often financed by companies which have a direct stake in selling synthetic fertilizers and pesticides.

It is difficult to make a strict distinction between uses and misuses of DDT. As a heuristic, we categorize misuse as (1) preventive use for a pest attack, (2) use of overdoses to make sure that a pest is killed, and (3) use of DDT as the primary tool to eradicate malaria. National governments in conjunction with World Health Organization (WHO) - a special division within the United Nations dedicated to public health issues - misused DDT in all three ways in the 1960s and 1970s. All three forms of misuse lead to excessive use, and increase the risk of resistance and uptake in organisms. Misuse of DDT is in this perspective overlapping with overuse.

\section{Societal impact}

One characteristic of DDT is that it is a broadly applied insecticide. It attacks many species indiscriminately, whereas some more modern pesticides are targeted at fewer species. As a pesticide, DDT enables the expansion of industrial agriculture systems, with profound effects on land use, biodiversity, and environmental quality. These wider social and environmental changes are often overlooked as people do not appreciate the role DDT played in making industrialized agriculture possible. From the 1930s onward, farmers in the US began intensifying their production by means of machines replacing human and horse labor, high-yielding hybrid seeds, and monoculture crop practices. This combination of farming methods spread around the world after the Second World War, with many developing countries taking up the practices in the 1960s, as part of the Green Revolution.

This type of agriculture is characterized by the removal of natural obstacles to work (e.g., draining water saturated soils, removing hedges) in favor of wide open spaces that could be more easily handled by machinery. Another consequence was that these vast surfaces were often turned into monoculture systems, i.e. one crop dominating at first in larger fields but very soon also across the whole landscapes. The increasing demands for food production, not only for human consumption but also for the production of feeds for 
cattle and pigs, created even higher pressure for increased productivity. Increased mono-cultural farming caused pests to become a more significant problem: with fields planted uniformly containing a single crop and without the natural pest control provided by beneficial insects and birds among diversified crops, the singular crops became more vulnerable to insect attacks. Without pesticide use, industrial agriculture would be less yielding, due to substantial losses from pest infection.

Table 2. Ethical issues and their adjacent short and long term effects

\begin{tabular}{|c|c|c|}
\hline Ethical Issues & Short term effects & Long term effects \\
\hline $\begin{array}{l}\text { Elimination of pests } \\
\text { in order to ensure and } \\
\text { increase outcome of } \\
\text { production in crops }\end{array}$ & $\begin{array}{l}\text { Successful elimination of pest, } \\
\text { Additional elimination and } \\
\text { impact on non-target organ- } \\
\text { isms, } \\
\text { Acute toxic effects likely to } \\
\text { be low in humans but not in } \\
\text { nature }\end{array}$ & $\begin{array}{l}\text { Accumulation in soils, } \\
\text { Effect at non-targets of the } \\
\text { whole ecosystem through } \\
\text { bio-concentration and bio- } \\
\text { magnification }\end{array}$ \\
\hline $\begin{array}{l}\text { Prevention of illness: } \\
\text { removal of insect- } \\
\text { borne vectors in } \\
\text { malaria, typhoid } \\
\text { control }\end{array}$ & $\begin{array}{l}\text { General improvement of life } \\
\text { conditions, } \\
\text { Elimination of diseases }\end{array}$ & $\begin{array}{l}\text { Induction of e.g. endocrine } \\
\text { disruption, } \\
\text { Re-appearance of disease } \\
\text { vectors }\end{array}$ \\
\hline Misuse/overuse & $\begin{array}{l}\text { Non-exploited doses build up } \\
\text { and left in crops and soils }\end{array}$ & $\begin{array}{l}\text { Resistance of organism } \\
\text { leading to no effect of use }\end{array}$ \\
\hline $\begin{array}{l}\text { Bio-concentration } \\
\text { and magnification }\end{array}$ & $\begin{array}{l}\text { Uptakes in tissues affecting } \\
\text { farmers and local populations, } \\
\text { Uptake in local as well as } \\
\text { migrating animals, } \\
\text { Binding in food and other } \\
\text { organic pools }\end{array}$ & $\begin{array}{l}\text { Residues found everywhere } \\
\text { far from use even in pristine } \\
\text { sub-arctic and arctic areas, } \\
\text { Ever increasing concentra- } \\
\text { tion and accumulation until } \\
\text { saturation or threshold } \\
\text { levels are reached }\end{array}$ \\
\hline $\begin{array}{l}\text { Mono-cultural food } \\
\text { production }\end{array}$ & $\begin{array}{l}\text { Monoculture can produce } \\
\text { more food in the shorter } \\
\text { term, } \\
\text { Gives less diversity in food, } \\
\text { leading to nutritional bias and } \\
\text { impact on health } \\
\text { A more vulnerable economical } \\
\text { system } \\
\text { Farmers in the developing } \\
\text { world are put in debt }\end{array}$ & $\begin{array}{l}\text { Lessened biodiversity, less } \\
\text { resilience and buffer capaci- } \\
\text { ty, } \\
\text { Potential eradication of } \\
\text { endangered (red-listed) and } \\
\text { protected species, } \\
\text { Local agricultural } \\
\text { knowledge disappears, } \\
\text { Induction of poverty } \\
\text { through instable economics }\end{array}$ \\
\hline
\end{tabular}

The impacts of use in agriculture are not limited to human and ecological health. Vandana Shiva $(1997,2000)$ has argued that mono-cultured food pro- 
duction endangers the local agricultural knowledge and indigenous practices that farming communities in developing countries have built up over centuries. Her claim is that modern Western industrial food production does not allow alternative production schemes: they are ridiculed, presented as irrational, or out-competed because so-called external costs are neglected. Shiva further claims that farmers in India can grow enough nutrition to feed the country if they cultivate biodiversity without chemicals.

To sum up, we point to the following intended consequences and short and long term adverse effects for human and ecological health, and societal impact of DDT:

- Increase and ensure production of crop plants,

- Prevention of insect-borne illness,

- Human and ecological health effects, including bio-concentration and bio-magnification,

- Overuse giving raise to resistance among target organisms and uptake in organisms,

- Agriculture based on monocultures that threats self-sustaining local communities.

An attempt to synthesize the considerations that enter our ethical analysis of DDT is shown in Table 2. The next step in our analytical process is to link the short and long-term effects of DDT to ethical values.

\section{Step 2: Linkages between consequences and ethical values}

According to the United Nations (UN 2015), the Earth's population will grow to 9.7 billion inhabitants by 2050 leading many to believe that food production will have to be increased correspondingly. In societies dominated by a growth in population - such as India and many nations on the African continent - an argument for using DDT as a pesticide is that it can contribute to increasing food production, and potentially support feeding an increasing number of inhabitants. This argumentation is linked to the ethical value of utility as increased food production can generate more well-being for a higher number of people because fewer will starve.

This reasoning is based on at least two premises: That the use of DDT is, and will be, the best way to increase food production and that the food will in fact reach an otherwise starving population.

A similar line of reasoning can be made for the use of DDT for combating diseases. How can we allow that 300 million people are annually infected with malaria when we have DDT to combat the vector organisms? These two intentional applications of DDT are linked to food and health security which values everybody's right to be safeguarded from hunger or illness. The uses 
of DDT also relate to the ethical value of justice. In the case of food production this concerns whether the food is distributed fairly, e.g. if the leastadvantaged members of society benefit from the increased production, or if they have access only to sprayed food products, whereas the privileged class enjoy organic and high quality meals. Justice is also involved if disease or health risks primarily affect certain vulnerable groups, e.g. children or poor people. We observe vector borne illnesses primarily in poorer regions, hence, the use of DDT to combat disease such as malaria can comply with justice.

An argument against the intentional use of DDT as a pesticide, and hence against increased food production, states that it in a long-term perspective violates the values of stewardship of the Earth and social stability. Such use and its long-term consequences supports population growth and a higher world population that is unsustainable both socially and environmentally. From a long-term perspective, societies should not focus on increasing food production, rather they should aim at decreasing population growth and hence minimize the need for growth in the production of food. These arguments address the long-term consequences of intentional use of DDT as a pesticide, whereas the former address short-term issues.

The ethical values of humility and precaution are at stake regarding the overuse of DDT resulting in a build-up of the residues in crops, soils, and animals. Harmful consequences of the overuse of DDT are today well documented, but were not foreseen before intensive over-use began. Both farmers and national governments, encouraged by the WHO, committed hubris when they tried to enhance crop yields or eradicate malaria by very excessive use of the chemical. We see this as a violation of the ethical value of humility as the use of DDT was seen as an omnipotent technology on which the solution to the problems of hunger and malaria was built. This approach also violates the principles of precaution as no preventive measures, such as the establishment of early warning mechanisms, were taken when DDT was used in large scale.

Today we know that overuse of DDT results in bioaccumulation and biomagnification. The bio-concentration of DDT means that organisms with tissues particularly rich in fats are more likely to suffer adverse health effects whereas bio-magnification signifies that organisms at higher levels of the biological hierarchy, i.e. predators, carry a higher risk of being affected. In this instance, the ethical values of stewardship of the Earth and respect for nature are involved. The intensive use of DDT cause ecosystems to be shifted out of balance and neglects their intrinsic value, suggesting that species and their environments must be protected not only directly through wild-life protection but also indirectly by sustained restrictions on DDT.

A less evident strike-back of intensive use of DDT occurs via the endocrine disrupting effect. This effect is not clearly understood and only supported by uncertain scientific evidence. Here, the precautionary principle is 
at stake and calls for preventive measures even when decisive scientific evidence is not at hand. Endocrine disruption is widespread over the animal kingdom, not only relating to human existence but also posing a threat to many other organisms, striking-back indirectly at society through the loss of biodiversity and diminishing ecosystem services. This aspect potentially risks human health and therefore possibly violates the ethical values of safety and security.

The use of DDT and other pesticides may have societal impacts in communities such as self-sustaining local communities that do not subscribe to the application of modern Western science and technology in food production, and instead practice an alternative, holistic, and low-technological way of producing food. Vandana Shiva $(1997,2000)$ has argued that the modern Western technologized approach to food production is no better than more diversified approaches. When it comes to forcing industrial and highly technologized food production methods onto poor farmers in self-sustaining local communities, the value of farmers' autonomy is violated. Also disregarded is a respect for nature due to the fact that mono-cultural agriculture practices violate biodiversity and are environmentally unsustainable.

A tentative conclusion based on the above identification of linkages between intentional actual use, potential misuse, adverse effects, and long-term consequences for society and culture and general ethical values may be represented in Table 3. The table is divided in two columns in which the first portrays the ethical issues identified in step 1 . The basic ethical values resulting in arguments for or against DDT use are listed in the second column.

Table 3. Main ethical issues of the use of DDT are linked to ethical values.

\begin{tabular}{ll} 
Issue & Linkage to ethical values \\
\hline $\begin{array}{l}\text { To increase food production by } \\
\text { protection of crops against pests }\end{array}$ & $\begin{array}{l}\text { In compliance with utility, food safety, } \\
\text { justice - if the food is distributed fairly; } \\
\text { In a long-term perspective, it violates social } \\
\text { stability and stewardship of the earth }\end{array}$ \\
$\begin{array}{l}\text { In compliance with utility, health safety, } \\
\text { vectors }\end{array}$ & $\begin{array}{l}\text { justice } \\
\text { Violation of humility, precaution } \\
\text { Bio-concentration and bio- } \\
\text { magnification }\end{array}$ \\
$\begin{array}{l}\text { Agriculture based on monocul- } \\
\text { tures }\end{array}$ & $\begin{array}{l}\text { Violation of stewardship for the earth, } \\
\text { respect for nature, safety and security }\end{array}$ \\
\hline
\end{tabular}




\section{Step 3: Identification of ethical dilemmas in using DDT}

To facilitate the identification of ethical dilemmas related to the use of DDT we will introduce a distinction between an unethical situation/action and an ethical dilemma. An unethical situation/action occurs when it violates ethical standards without being justified by reference to other ethical standards. An ethical dilemma is defined as a situation where different ethical standards are in collision or where there is a collision of different interpretations of the same standard.

\section{Use of DDT must be regulated and restricted to prevent overuse}

Our quick ethical analysis suggests that the overuse of DDT is unethical and cannot be justified as it violates safety and security, humility, precaution, stewardship of the Earth, and respect for nature, while also casting doubts on the long-term benefits of using DDT. High rates of DDT use must be avoided.

Use of DDT in agriculture is not ethical; modest use of DDT to combat malaria is

A distinction must be made between two purposes of use of DDT. In one case, it was introduced to ensure sufficient food production, the other was due to a wish to increase life quality by eliminating the vectors that transfer harmful disease. This distinction is especially important as the use of DDT must be restricted to avoid overuse, therefore arguing for each case becomes relevant. Alternatives to the use of DDT in malaria prevention is not foreseen to emerge in near future, whereas we will argue that the use of DDT should not be allowed in agriculture as alternative pesticides do exist that can replace the compound in that case.

\section{Anthropocentric versus environmental concerns}

We identify an ethical dilemma, which we formulate as a question: Can the utility, safety, and security that a moderate use of DDT provides in our combat against disease be justified at the cost of (i) our stewardship for the earth and respect for nature, and/or (ii) uncertain potential negative consequences associated with a moderate use of DDT?

The first part of this question reflects two different perceptions of the relationship between humans and nature. Is humanity something different from the surrounding nature, a threat we need to be protected from? Or do we see the natural environment as a part of our humanity?

Killing a target organism is one thing and reflects the first perspective on the human/nature relationship. Target organisms are considered a threat to 
humanity's well-being. Accidental killing of non-target organisms and all other unintended environmental effects aligns with the second position on the human/nature relationship. Even a moderate use of DDT influences the environment, and if one believes that our natural environment is defining ourselves as human beings, it becomes difficult to justify a moderate use of DDT because we, in that way, jeopardize our humanity.

Most likely this ethical concern is more easily overcome when we consider organisms at the lower levels of the biological hierarchy, such as insects, as they, on a mere physiological basis, have no spine, little brain, and are not able to sense pain. The situation becomes different when the organisms affected are to be found higher up in the hierarchy, such as predatory birds and polar bears, or if the natural environment changes appearance. The suspected effects on various higher level animals are generally sub-lethal and may be considered acceptable when judged from an anthropocentric ethical point of view, such as utilitarianism. On the other hand, when effects are concerned with the ability of organisms to reproduce, such an effect may have severe effects on the natural environment in the first instance and on the human population in a long-term perspective. In such a scenario, the two different perspectives on the human/nature relationship overlap.

Regarding the second part of the question we see that, on one hand, humans are being exposed to an array of potential health damages, particularly when DDT is sprayed inside their houses. One type of adverse effect, that of endocrine disruption, can strike anywhere with seemingly no particular social or sexual differentiation. The endocrine disrupting effect has been demonstrated to affect both males and females. However, these effects are not fully understood and might not materialize if the use of DDT is restricted and used with care.

On the other hand, humans - especially those in developing countries with poor public health infrastructure - surely benefit from the control or even elimination of insect vectors and the resulting lessening of their disease burdens. Malaria and other diseases that can be regulated by use of DDT are usually found in regions of the world dominated by 3rd world countries in general, and Africa, South America, and South East Asia in particular. If 300 million incidents of malaria correspond to an additional cost in GDP of 12 billion it means an extra increase in GDP of 4,000 US\$ per incident that is avoided. In fact, this number exceeds the per capita GDP of many African countries. 
Step 4: Technological and institutional design criteria to transcend dilemmas.

\section{Legislation}

The presence of DDT in food and the environment was first detected in the 1960s more than two decades after its introduction (Watson 2001). By the late 1960s, countries began to withdraw DDT as a malaria control agent partly due to the environmental effects and partly because of drainage efforts and the removal of wetlands resulting in the reduction of vector survival places. DDT was, in 1972, banned in the US with many other nations implementing similar bans shortly after.

The use DDT is now regulated under the Stockholm Convention (2008) that has been signed - but not ratified - by 180 countries. Today it is illegal to use DDT with the purpose of protecting crops against pests. Through the period of extensive use in agriculture the use of DDT increased to more than 40,000 tons per year (with a peak production of 82,000 in 1963). As a result of the restrictions the production decreased to approximately 3,300 tons in 2009.

Recently, the restricted use of the compound for eradicating disease vectors has been lifted in the Stockholm Convention. Hence, one may identify countries where the usage to fight vector borne diseases is allowed. The WHO's policy is to recommend DDT use as part of a management package in high transmission areas where the degree of control must be particularly high. During the 2000s, some countries, mostly in Africa, resumed using DDT to control malaria as their mosquito populations have become more resistant to other pesticides. Enforcement of the treaty is also a concern.

Our ethical analysis supports the international legislation restricting the use of DDT. We judge that legislation as sound and ethically justified.

\section{Holistic alternatives to pesticides in agriculture}

The previous step of our ethical analysis points to expanding available alternatives to the use of DDT in agriculture (and in the combat against vectorborne diseases). A measure to do this is to transform industrialized agriculture methods into more environmentally friendly practices through organic agriculture. Increasing hedges and biodiversity in the landscape would enhance predators of pests which have been found to be equally efficient to the use of pesticides. The development of new pesticides and other technological agriculture practices to prevent pest attack in mono-cultural agriculture is also a possibility if ethical standards (e.g. farmers' autonomy or precaution) are not violated.

There exist many alternatives to intensive forms of agriculture - known under names such as organic agriculture, agroecology, polycultures, perma- 
cultures, etc., all of which are forms of soil exploitation which involve working closer to natural principles and include higher biodiversity, soil conservation, the input of nutrients by use of leguminous plants, higher diversity landscapes, and even exploitation of the $3^{\text {rd }}$ dimension i.e. production at various levels of height.

There is convincing evidence that advantages exist which are connected to such ways of growing crops. In particular, organic agriculture and agroecology encourage the use of biological and ecological methods for controlling pests. These include maintaining hedgerows that sustain predatory organisms like wasps or birds, planting multiple crops together to reduce the likelihood of pest or disease outbreak, and using methods like the push-pull model developed in Kenya. These methods can greatly reduce the demand for pesticides. Simultaneously, such farming systems have a more continuous demand for labor that may be handled within a family and have a higher crop range that can provide a more nutritious selection of food. Last, but not least, such a system is less vulnerable to economic oscillations in market prices.

On the other hand, alternative pesticides provide us with technological solutions that are easy to apply. As long as the consumption of pesticides is restricted or not over-used but applied with care they can provide alternatives to DDT use. An expansion of available alternatives to include holistic approaches in agriculture will not prevent the use of pesticides in cases where these options are autonomously chosen by farmers and local communities.

\section{Alternatives to DDT in prevention of vector-borne diseases}

More challenging is finding ways to reduce the use of DDT for inhibiting vector organisms in order to interfere with the spread of diseases. The argument goes that malaria is, in a number of ways, not only disastrous to human health, but also costly to society in a many developing countries (for a list of viewpoints, see Zelson 2014), and that no other solutions exist. Despite this, the Stockholm treaty calls for DDT to be phased out over time. The history of DDT shows that the insecticide was initially very effective in the 1950 s before succumbing to the growth of pest resistance in the 1960s. However, this resistance tends to disappear with time and, as a result, treatments with DDT become effective again. By 2000, when several developing countries, notably South Africa and India, reinitiated the spraying of DDT, the insecticide was proven to be very efficient. However, by 2011, pest resistance had already re-emerged on a widespread scale across Africa.

Other technological solutions might have longer-lasting effects than periodically reviving DDT. These solutions include the deliberate spread of male mosquitoes that have been made infertile through radiation, thus lowering their reproductive success, but not without many obstacles (e.g., there can still be fertile mosquitoes). Research in and development of new 'gene drive' 
technology is now being tested in Brazil to genetically modify mosquitoes to be infertile (Mendes 2012). This is a radical novel technological intervention that in itself is suitable for being ethically evaluated. Here the questions on long-term effects of eradicating a whole complexion of species will have to be addressed.

Alternatively, insect habitat control measures and behavioral change steps can be taken in combination, without necessarily needing any of these technologies. The question is how far can we go by widespread implementation and dissemination in the use of nets, repair and manipulation of the ambient environment, removal of open waters (sewers, gutters, and rainwater puddles), and regulation of indoor temperature and humidity - all factors that will impact the reproduction and survival in the vector populations.

\section{Early warning mechanisms}

The DDT case is an example of a chemical boomerang. On one hand, we are reliant on quite a large number of chemicals offering benefits to us such as the increased availability of food by means of increased crop growth, or improved public health through medicines and disease control. On the other hand, some of these chemicals have at a later stage been found to produce negative impacts. The challenge arises as how to evaluate the positive and negative effects and how to balance those up against each other.

The question is whether we can accept the high number of chemical boomerangs and sputniks and, if so, which ones call for ethical judgment. Should we eliminate the use of pesticides and accept more people dying from hunger or from one of the many diseases having insects as a vector? The number of ethical questions that even one chemical substance raises is endless and although it is possible to group some chemicals, their relating effects tend to be so specific and unique that almost every chemical requires its own assessment. This can be seen in the two volumes of the Late lessons from early warnings series issued by the European Environment Agency which consists of an extensive list of case studies relating to industrial pollutants (EEA 2001, 2013). Unfortunately, individualized studies are not likely to be possible if we attempt to make full toxicological screening on the most important high volume substances.

An important point made in Our Stolen Future (Colborn et al 1993) is that existing risk assessment tools cannot foresee undesired consequences of chemical compounds - such effects may be completely new.

One reaction to this issue is to set up early warning measures with the purpose of spotting new undesirable effects for human health and the environment. These could try to spot weak indicators in the scientific literature. When indicators of new, unwanted, and potentially dangerous effects are recognized, resources to further research in those potential effects are allo- 
cated to further research so that it can be decided whether the potential effect is real or not. Early warning mechanisms can be included within existing legal regimes regulating the use of industrial pollutants, e.g. into the Stockholm Convention.

\section{Conclusion}

In this paper, we have presented a quick and proper method for making ethical assessments of the use of industrial chemicals, and applied it to the use of DDT. The model has helped the authors to form their ethical judgment on the use of DDT. Based on the analysis,

- We recommend that the use of DDT must be heavily regulated to prevent overuse. The Stockholm Convention provides an ethically sound legal framework for the regulation of DDT.

- We do not identify persuasive ethical arguments for the use of DDT in agriculture as alternatives exist both in the form of target-specific pesticides and by means of holistic agricultural approaches. We suggest that it becomes more widely accepted to choose holistic alternatives, and that barriers for making this choice are lowered.

- We find that a modest use of DDT in the fight against malaria is ethically justified until better alternatives are available.

- It is suggested that early warning mechanisms are set up to spot unforeseen effects of the alternatives developed to replace DDT in both agriculture and in the domain of public health.

- An ethical dilemma is identified between the benefits provided by a modest use of DDT in combatting malaria and the effect on nature's integrity and the potential negative consequences related to the moderate use of DDT. The authors encourage students of chemistry and chemical engineering to discuss how to transcend that dilemma.

An ethical estimate is never final and objective. Hence, we encourage our readers to make their own ethical judgment, and challenge our conclusions.

\section{Acknowledgement}

We would like to thank Joachim Schummer and two anonymous reviewers for valuable comments and suggestions. The Centre for Ethics in Practice at Aalborg University is acknowledged for funding this work. 


\section{Further Reading}

A much more detailed presentation of common-sense morality is found in Beauchamp \& Childress 2001. An expanded discussion of most of the ethical values presented here is found in Resnik 2012. For a more detailed and thorough presentation of the history of DDT we refer to Bouwman et al. 2013 and chapter two in Widavsky 1995. Carson 1962 and Colburn et al. 1993 are influential historical items still worthwhile reading.

\section{References}

Aktar, W.; Sengupta, D. \& Chowdhury, A.: 2009, 'Impacts of pesticides use in agriculture: their benefits and hazards', Interdisciplinary Toxicology, 2(1), 1-12.

Beamon, B.M.: 2005, 'Environmental and Sustainability Ethics in Supply Chain Management', Science and Engineering Ethics, 11, 221-234.

Beauchamp, T.L. \& Childress, J.F.: 2001, Principles of biomedical ethics, New York: Oxford University Press.

Bond, J.: 2009, 'Professional ethics and corporate social responsibility', Process Safety and Environmental Protection, 87, 184-190.

Borgå, K.; Gabrielsen, G.W. \& Skaare, J.U.: 2001, Biomagnification of organochlorines along a Barents Sea food chain, Environmental Pollution, 113, 187-198.

Bouwman, H.; Bornman, R.; van den Berg, H. \& Kylin, H.: 2013, 'DDT: fifty years since Silent Spring', in: EEA (ed.), Late Lessons from Early Warnings: Science, Precaution, Innovation, Copenhagen: EEA, pp. 240-259.

Børsen Hansen, T.; 2005: Teaching Ethics to Science and Engineering Students, Copenhagen: Center for the Philosophy of Nature and Science Studies [available online at: http://portal.unesco.org/shs/en/files/8735/11289332261 TeachingEthics_CopenhagenReport.pdf/TeachingEthics_CopenhagenReport.pdf, accessed 28 October 20167.

Børsen, T. \& Danborg, P.B.: 2015, 'Techno-Anthropological Ethics and Health Information Systems Technologies', in: Botin, L.; Bertelsen, P. \& Nøhr, C. (eds.), Techno-Anthropology in Health Informatics: Methodologies for Improving Human-Technology Relations, Technology and Informatics, Amsterdam: IOS Press, pp. 83-94.

Carson, R.: 2000 [1962], Silent Spring. London: Penguin.

Colburn, T.; Dumanoski, D. \& Myers, J.P.: 1996, Our Stolen Future: Are We Threatening Our Fertility, Intelligence, and Survival? A Scientific Detective Story, London: Penguin.

Colburn, T.; vom Saal, F.S. \& Soto, A.M.: 1993, 'Developmental Effects of Endocrine-Disrupting Chemicals in Wildlife and Humans', Environmental Health Perspectives, 101 (5), 378-384.

Cone, M.: 2009, 'Should DDT be Used to Combat Malaria?', Scientific American, Environmental Health News, May 4 [available online at: http://www.scientificamerican.com/article/ddt-use-to-combat-malaria, accessed 26 April 2016].

Davis, M.: 2002, 'Do the Professional Ethics of Chemists and Engineers Differ?', HYLE: International Journal for Philosophy of Chemistry, 8 (1), 21-34. 
EEA: 2001, Late Lessons from Early Warnings: the Precautionary Principle 1896-2000, Copenhagen: EEA [available online at: http://www.eea.europa.eu/publications /environmental_issue_report_2001_22, accessed 28 October 2016].

EEA: 2013, Late Lessons from Early Warnings: Science, Precaution, Innovation, Copenhagen: EEA, [available online at: http://www.eea.europa.eu/ publications/late-lessons-2, accessed 28 October 2016].

EEA: 2015, Priority Substances and Certain Other Pollutants according to Annex II of Directive 2008/105/EC. Copenhagen: EEA, [update from 8 June 2016 available online at: http://ec.europa.eu/environment/water/water-framework/ priority_substances.htm, accessed 28 October 2016].

EU: 2000, Communication from the commission on the precautionary principle COM 1, Brussels: Commission of the European Communities [available online at: http://eur-lex.europa.eu/LexUriServ/LexUriServ.do? uri=COM:2000:0001: FIN:EN:PDF, accessed 31 March 2017].

Hård, M. \& Jamison, A.: 2005, Hubris and Hybrids. A cultural history of philosophy and science, New York \& London: Routledge.

Hellweg, S. \& Frischknecht, R.: 2004, 'Evaluation of Long-Term Impacts in LCA', The International Journal of Life Cycle Assessment, 9 (5), 339-341.

Johansen, B.E.: 2003, The Dirty Dozen. Toxic Chemicals and the Earth's Future, Connecticut \& London: Westport.

Jonas, H.: 1984, The Imperative of Responsibility. In Search of an Ethics for the Technological Age, Chicago \& London: University of Chicago Press.

Leblanc, G.A.: 1995, 'Trophic-Level Differences in the Bioconcentration of Chemicals: Implications in Assessing Environmental Biomagnification', Environmental Science E Technology, 29, 154-160.

Mendes, H., 2012. Brazil tests GM mosquitoes to fight Dengue, Nature, News and Comments article [available online at: http://www.nature.com/news/braziltests-gm-mosquitoes-to-fight-dengue-1.10426, accessed 28 October 2016].

Næss, A.: 1973, 'The shallow and the Deep, Long-range Ecology Movement', Inquiry, 16, 95-100.

Parke, D.V.: 1995, 'Ethical Aspects of the Safety of Medicines and other Social Chemicals', Science and Engineering Ethics, 1, 283-298.

Petrosyan, P.S.: 2011, 'Chemical Safety Problems', Conservation Science in Cultural Heritage: Historical-technical Journal, 11 [available online at: https://conservation-science.unibo.it/article/view/2693/2092, accessed 31 March 2017].

Preston, C.J.: 2005, 'The Promise and Threat of Nanotechnology: Can Environmental Ethics Guide Us?' HYLE: International Journal for Philosophy of Chemistry, $11,1,19-44$.

Resnik, D.B.: 2012, Environmental Health Ethics, Cambridge: Cambridge University Press.

Shiva, V.: 1997, Monocultures of the mind: Perspectives on Biodiversity and Biotechnology, London \& New York: Zed Books \& Third World Network.

Shiva, V.: 2000, Stolen Harvest: The hijacking of the global food supply, Boston, Massachusetts: South End.

Stockholm Convention: 2008, Listing of POPs in the Stockholm Convention [available online at: http://chm.pops.int/TheConvention/ThePOPs/ListingofPOPs/ tabid/2509/Default.aspx, accessed 28 October 2016].

Strandberg, B.; Bandh, C.; van Bavel, B.; Bergqvist, P.-A.; Broman, D.; Näf, C.; Pettersen, H. \& Rappe, C.: 1998, 'Concentrations, biomagnification and spatial variation of organochlorine compunds in a pelagic food web in the northern part of the Baltic Sea', The Science of the Total Environment, 217, 143-154. 
UNEP: 2015, Stockholm Convention on Persistent Organic Pollutants. Report from Conference to the Stockholm Convention on Persistent Organic Pollutants. Seventh Meeting, Geneva, 4-15 May, 2015 (UNEP/POPS/COP.7/INF/5).

UNICEF: 2004, Fact Sheet: Malaria a Global Crisis [available online at: http://www.unicef.org/media/media_20475.html, accessed 27 October 2016].

United Nations: 2015, World Population Prospects: The 2015 Revision, United Nations, Department of Economic and Social Affairs/Population Division.

Wang, X. \& Wang, W.-X.: 2005, 'Uptake, absorption efficiency and elimination of DDT in mariner phytoplankton, copepods and fish', Environmental Pollution, 136, 453-464.

Watson, D.H.: 2001, Food Chemical Safety, Boca Raton: CRC, Woodhead, vol 1.

Wildavsky, A.: 1995, But is it True? A citizen's guide to environmental health and safety issues, Cambridge, MA \& London: Harvard University Press.

Zelson, E.: 2014, 'Rethinking DDT: The Misguided Goals of the Stockholm Convention on Persistent Organic Pollutants and a Plan to Fight Malaria Worldwide', William E Mary Environmental Law E Policy Review, 243, [available online at: http://scholarship.law.wm.edu/wmelpr/vol39/iss1/8/, accessed 28 October 2016].

Tom Børsen and Søren Nors Nielsen:

Department of Development and Planning, University of Aalborg Copenhagen,Denmark; boersen@plan.aau.dk,nors@plan.aau.dk 